\title{
Evaluation of two cane instruments in older adults with knee osteoarthritis
}

\author{
Nancy Harada, PT, PhD; ${ }^{1-2}$ Stephanie Fong; ${ }^{1}$ Constance Heiney, MS; ${ }^{1}$ Jennifer M. Yentes, PhD; ${ }^{3}$ Karen L. \\ Perell-Gerson, PhD; ${ }^{1,4}$ Meika A. Fang, MD $^{1-2 *}$ \\ ${ }^{1}$ Department of Veterans Affairs Greater Los Angeles Healthcare System, Los Angeles, CA; ${ }^{2}$ David Geffen School of \\ Medicine, University of California, Los Angeles, Los Angeles, CA; ${ }^{3}$ Nebraska Biomechanics Core Facility, University of \\ Nebraska at Omaha, Omaha, NE; ${ }^{4}$ School of Science and Technology, Georgia Gwinnett College, Lawrenceville, GA
}

\begin{abstract}
The objectives of this study were to describe the psychometric properties of the Cane Cognitive Mediator Scale (CCMS) and the Psychosocial Impact of Assistive Devices Scale (PIADS) in adults with knee osteoarthritis (OA) and to determine the feasibility of applying these instruments as screening tools to identify patients with the propensity to use a cane. Data from a randomized crossover trial were analyzed for 53 older adults with knee OA. Perceptions on using a cane were measured at baseline using the CCMS and PIADS. The CCMS was repeated $1 \mathrm{wk}$ later. At 6 mo, subjects rated their intention to use a cane. The findings indicated that $1 \mathrm{wk}$ test-retest reliability was acceptable for the CCMS Attitudes and Subjective Norms subscales ( $r=0.48$ to 0.93 ) and low for the CCMS Perceived Behavioral Control subscale ( $r=0.15)$. Internal consistency reliability was good for each CCMS and PIADS subscale. The CCMS Subjective Norms subscale demonstrated acceptable predictive validity across all subgroups ( $r=0.53$ to 0.88 ). The PIADS Adaptability subscale demonstrated acceptable predictive validity for the 45 to 64 yr-old age group ( $r=0.54$ ). The findings indicate that the CCMS Subjective Norms subscale exhibits good psychometric properties and has potential application as a screening tool.
\end{abstract}

Clinical Trial Registration: ClinicalTrials.gov; NCT00223795. "Walking aids in the management of knee osteoarthritis; http://www.clinicaltrails.gov/ct2/show/NCT00223795

Key words: assistive device, cane use, knee, older adults, osteoarthritis, psychosocial, rehabilitation, reliability, screening, validity.

\section{INTRODUCTION}

An estimated one-third of all older adults currently use an assistive device [1]. As the older adult population continues to grow, the demand for assistive devices will likely increase. Despite the widespread use of assistive devices, studies have found high rates of abandonment ranging from 8 to 75 percent [2]. From a clinical standpoint, assistive devices such as canes and walkers are prescribed to patients to minimize disability. The extent to which an older adult chooses to use a prescribed assistive device may influence how long he or she will remain functionally independent. One may speculate that an older adult who chooses to adopt a prescribed assistive device may develop the ability to better cope with future physical and mental challenges.

\footnotetext{
Abbreviations: CCMS = Cane Cognitive Mediator Scale, OA = osteoarthritis, PIADS = Psychosocial Impact of Assistive Devices Scale, QUEST = Quebec User Evaluation of Satisfaction with Assistive Technology, VA = Department of Veterans Affairs, WOMAC = Western Ontario and McMaster Universities Osteoarthritis Index.

*Address all correspondence to Meika A. Fang, MD; VA Greater Los Angeles Healthcare System (111J), 11301 Wilshire Blvd, Los Angeles, CA 90073-1003; 310-268-4503; fax: 310-268-4250. Email: Meika.Fang@va.gov http://dx.doi.org/10.1682/JRRD.2013.06.0140
} 
Psychosocial factors may influence older adults' use of commonly prescribed assistive devices. Furthermore, these psychosocial factors may ultimately determine device adoption, retention, and/or abandonment [3]. Thus, clinicians must evaluate psychosocial factors influencing assistive device use because patients' personal beliefs often influence their ongoing compliance with use of the device [4].

A review of the literature yielded several survey instruments that have been developed to measure psychosocial factors influencing assistive device use. The Quebec User Evaluation of Satisfaction with Assistive Technology (QUEST) was developed by Demers and colleagues [5] and targets current users of an assistive device. The QUEST is designed to measure satisfaction with a broad range of assistive technology and asks respondents how satisfied they are with specific features such as weight, height, length, width, and some characteristics of the services related to the device, i.e., repairs and servicing [5]. In another study, Roelands and colleagues developed separate subscales for community-dwelling older adults living in Belgium to measure awareness, possession and use of assistive devices, attitudes toward use, self-efficacy, and intention to use assistive devices [6].

The Psychosocial Impact of Assistive Devices Scale (PIADS) [3] and the Cane Cognitive Mediator Scale (CCMS) [4] also measure perceptions of assistive device use in older adults. Both these instruments can be administered to individuals even if they are not current assistive device users, thus providing information on how an assistive device would affect them. The PIADS was developed to measure the effect of an assistive device (e.g., all categories of assistive technology and not limited to any one type) on quality of life and sense of well-being [3]. The PIADS may also be used to assess a respondent's expectations of using a device before its actual use. In contrast, the CCMS was developed to assess psychosocial factors specifically related to using a cane. The CCMS was developed based on the theory of planned behavior, which may be applied to explain the performance or nonperformance of a health behavior [4]. The theory states that the intention to perform a behavior is determined by attitudes toward the behavior, perceived social pressure, and perceived behavioral control in engaging in the behavior. For example, the use of a cane by an older adult (behavior performance) may be influenced by what his or her family thinks (perceived social pressure) and the costs of obtaining a cane (behavioral control).
The aim of this study was to compare simultaneously the psychometric properties of the PIADS and CCMS in older adults with osteoarthritis (OA) of the knee. Specifically, we examined the test-retest reliability (CCMS only), internal consistency reliability, and predictive validity of these instruments in order to identify which of these instruments, or subscales of these instruments, could assist the clinician in determining a patient's willingness to use an assistive device before training.

\section{METHODS}

\section{Setting and Participants}

The data used for this analysis were derived from a randomized crossover trial whose overall aim was to investigate the effects of cane use on spatiotemporal gait parameters in patients with knee OA. This study was conducted at the Department of Veterans Affairs (VA) West Los Angeles Healthcare Center, an urban tertiary academic hospital.

Fifty-three community-dwelling subjects with knee OA were recruited for the study. The diagnosis of knee OA was made based on clinical and radiographic criteria [7]. Inclusion criteria included unilateral knee pain on movement, which was scored at $\geq 35 \mathrm{~mm}$ on a $100 \mathrm{~mm}$ visual analog scale for most days of the previous month [8-10]; age 45 to $85 \mathrm{yr}$; ability to walk $30 \mathrm{ft}$ without noticeably severe postural sway that might indicate the need for additional support such as a walker; ability to stand unaided; no cane use in past $30 \mathrm{~d}$; body mass index $>25 \mathrm{~kg} / \mathrm{m}^{2}$; weight $<300 \mathrm{lb}$; fulfillment of the American College of Rheumatology criteria for knee OA [11]; and radiographic Kellgren-Lawrence scale knee OA grade $\geq 1$ [7]. Individuals were excluded if they had prior knee trauma or surgery, including arthroscopic surgery, within the past 6 mo; upper-body weakness; injury or amputation to the lower-limb joints; symptomatic spine, hip, ankle, or foot disease that would interfere with assessment of the knee; poor health that would impair compliance or assessment, such as shortness of breath with exertion; neurological disease including vestibular dysfunction; or impaired vision. Subjects who were taking acetaminophen or nonsteroidal anti-inflammatory drugs at study entry were permitted to continue taking these medications as they had previously. 


\section{Self-Report Cane Surveys}

The properties of the two surveys are outlined in Table 1. The PIADS was originally developed to measure the effect of glasses and contact lenses on quality of life in college students. The instrument went through two iterations of development. The final version consists of 26 items, with each item describing a possible effect of using the assistive device. The user is asked to rate how he or she feels about each item on a scale from -3 (indicating the most negative impact) to +3 (indicating the most positive impact). For example, the user is asked to rate how the assistive device affects his or her "sense of control" or

Table 1.

Summary of Cane Cognitive Mediator Scale (CCMS) and Psychosocial Impact of Assistive Devices Scale (PIADS) cane use measures.

\begin{tabular}{|c|c|c|}
\hline Variable & CCMS & PIADS \\
\hline Intended Application & $\begin{array}{l}\text { Measures intention to use cane based on theory } \\
\text { of planned behavior constructs: attitude, per- } \\
\text { ceived social pressure, and ease/difficulty of } \\
\text { engaging in behavior of using cane. }\end{array}$ & $\begin{array}{l}\text { Measures effect of assistive device (all categories } \\
\text { of assistive technology) on quality of life and sense } \\
\text { of well-being. Specifically, measures effect on } \\
\text { competence (functional independence, perfor- } \\
\text { mance, and productivity), adaptability (willingness } \\
\text { to try new things), and self-esteem (extent to which } \\
\text { assistive device affects emotional well-being). }\end{array}$ \\
\hline Mode of Administration & Self-administered or interviewer-administered. & Self-administered. \\
\hline Time to Complete & 5 to $10 \mathrm{~min}$. & 5 to $10 \mathrm{~min}$. \\
\hline Number of Items & $\begin{array}{l}24 \text { items (13 measuring attitude, } 4 \text { measuring } \\
\text { social pressure, and } 7 \text { measuring ease/difficulty } \\
\text { of using cane. }\end{array}$ & 26 items. \\
\hline Derived Measures & $\begin{array}{l}3 \text { subscales: } \\
\text { - Attitudes (sum of } 13 \text { beliefs about psychosocial, } \\
\text { functional, and safety consequences of cane use. } \\
\text { Total subscale score ranges from }-26 \text { to }+26 \text { ). } \\
\text { - Subjective Norms (score on } 4 \text { normative belief } \\
\text { items times corresponding motivation to comply. } \\
\text { Total subscale score ranges from }-40 \text { to }+40 \text { ). } \\
\text { - Perceived Behavioral Control (sum of } 7 \text { beliefs } \\
\text { about cane use. Total subscale score ranges from } \\
-14 \text { to }+14 \text { ). }\end{array}$ & $\begin{array}{l}3 \text { subscales: } \\
\text { - Competence (items ask about competence, produc- } \\
\text { tivity, usefulness, performance, and independence. } \\
\text { Subscale score is mean of } 12 \text { items and ranges from } \\
-3 \text { to }+3 \text { ). } \\
\text { - Adaptability (items ask about ability to participate, } \\
\text { willingness to take chances, eagerness to try new } \\
\text { things, and ability to take advantage of opportuni- } \\
\text { ties. Subscale score is mean of } 6 \text { items and ranges } \\
\text { from -3 to +3). } \\
\text { - Self-esteem (items ask about self-esteem, security, } \\
\text { sense of power and control, and self confidence. } \\
\text { Subscale score is mean of } 8 \text { items and ranges from } \\
-3 \text { to }+3 \text { ). }\end{array}$ \\
\hline How to Obtain Instrument & Aminzadeh and Edwards [4]. & $\begin{array}{l}\text { Free from Department of Physical Medicine and } \\
\text { Rehabilitation, University of Western Ontario. }\end{array}$ \\
\hline
\end{tabular}


"willingness to take chances." Scoring on the PIADS yields three subscale scores that were derived through factor analysis and a total score. The Competence subscale consists of 12 items, the Adaptability scale consists of 6 items, and the Self-Esteem scale consists of 8 items. Each of the subscales, as well as the total score, is computed by obtaining the mean of all items within that subscale or full scale, so that each subscale score ranges from -3 to +3 . Internal consistency reliability is high, as demonstrated by a Cronbach alpha of 0.95 for the total score and 0.92, 0.88 , and 0.87 for the Competence, Adaptability, and SelfEsteem subscales, respectively [12].

The CCMS was developed for older adults in order to assess beliefs about the consequences of cane use. The instrument consists of three subscales measuring attitude (13 items), social pressure (4 items), and ease/difficulty of engaging in the behavior of using a cane (7 items). Each item is scored on a 5-point Likert scale ranging from -2 (very unlikely) to +2 (very likely). Three subscale scores are derived: the Attitudes subscale is the sum of 13 beliefs, the Subjective Norms subscale score is the sum of item scores on 4 social pressure items multiplied by the corresponding motivation to comply with these referents, and the Perceived Behavioral Control subscale score is the sum of 7 beliefs about ease/difficulty in engaging in cane use. Known-groups validity of the CCMS has been demonstrated on a sample of community-living seniors in which significant differences $(p<$ 0.001 ) were found between cane users and cane nonusers [4]. Cane users reported more positive attitudes, perceived greater social expectations to use a cane, and anticipated fewer difficulties in successfully using a cane. Internal consistency reliability is high, as demonstrated by Cronbach alpha coefficients ranging from 0.81 to 0.96 for all subscales [4].

\section{Procedure}

Subjects $(n=53)$ were measured at baseline on the PIADS and CCMS, and the CCMS was repeated at week 1 ( $n=53$ ) before randomization to cane and no-cane user groups. Baseline knee OA symptoms were evaluated at baseline using the Western Ontario and McMaster Universities Osteoarthritis Index (WOMAC), a validated and disease-specific questionnaire separately addressing severity of joint pain, stiffness, and limitation of physical function experienced during the $24 \mathrm{~h}$ before assessment [13]. Each item on the WOMAC Pain, Stiffness, and Functional Activity subscales asks subjects to rate their degree of pain, stiff- ness, or difficulty in performing activities on a scale ranging from 0 (no pain, stiffness, or difficulty) to 100 (extreme pain, stiffness, or difficulty). At the 2 mo visit, all participants were given single-point canes to use as often as they desired. At the 6 mo visit, each subject was asked to rate his or her intention to continue to use a cane in the next month on a 5-point Likert scale ranging from very unlikely to very likely.

\section{Data Analysis}

Descriptive statistics, including frequencies and measures of central tendency and dispersion, were conducted to evaluate the distributional characteristics of each demographic variable. Descriptive statistics for each CCMS and PIADS subscale score were calculated for the total sample and by subgroup (cane users/cane nonusers and sex). Pearson correlation coefficients were calculated to assess the 1 wk test-retest reliability of the CCMS. Cronbach alpha coefficients were calculated to determine the internal consistency reliability of both the CCMS and PIADS. Predictive validity was assessed by calculating Pearson correlation coefficients between each CCMS or PIADS subscale at baseline and use of the cane at 6 mo for the total sample and by subgroup. All analyses were conducted using PASW, version 18 (IBM Corporation; Armonk, New York) [14].

\section{RESULTS}

\section{Sample Characteristics}

Demographic and clinical characteristics of the sample are presented in Table 2 . There were significant associations between cane use/cane nonuse with sex, race, education, and OA involvement $(p \leq 0.05)$. Of the 26 subjects who were cane nonusers, 19 had never used a cane before enrolling in this study. The average age of the total sample was $59.5 \mathrm{yr}$, with a range of 46 to $84 \mathrm{yr}$. The majority of the sample (70.3\%) was male. The racial breakdown of the participants was 40.6 percent black, 28.1 percent white, and 14.1 percent other race. Sixty-eight percent of all respondents had education greater than high school level. In the total sample, 76.5 percent had bilateral knee involvement. The mean total WOMAC subscale scores for Pain, Stiffness, and Functional Activity were 244.3 out of $500,119.9$ out of 200 , and 902.1 out of 1,700 , respectively.

Descriptive statistics for the CCMS and PIADS are displayed in Table 3. Mean scores on each CCMS or 
Table 2.

Subject demographic and clinical characteristics.

\begin{tabular}{|c|c|c|c|}
\hline Demographic/Characteristic & Cane Users $(n=27)$ & Cane Nonusers $(n=26)$ & Total Sample $(n=53)$ \\
\hline \multicolumn{4}{|l|}{ Age (yr) } \\
\hline Mean \pm SD & $59.1 \pm 8.9$ & $59.9 \pm 8.4$ & $59.5 \pm 8.6$ \\
\hline Range & $49-84$ & $46-78$ & $46-84$ \\
\hline \multicolumn{4}{|l|}{$\operatorname{Sex}(n, \%)^{*}$} \\
\hline Male & 20 (76.9) & $25(92.6)$ & 45 (70.3) \\
\hline Female & $6(23.1)$ & $2(7.4)$ & $8(12.5)$ \\
\hline \multicolumn{4}{|l|}{ Race $(n, \%)^{*}$} \\
\hline White & $5(19.2)$ & $13(48.1)$ & $18(28.1)$ \\
\hline Black & $17(65.4)$ & 9 (33.3) & $26(40.6)$ \\
\hline Other & $4(15.4)$ & $5(18.5)$ & $9(14.1)$ \\
\hline \multicolumn{4}{|l|}{ Education $(n, \%)^{*}$} \\
\hline Less than High School & $3(11.5)$ & $5(18.5)$ & $8(15.0)$ \\
\hline High school & $6(23.1)$ & $3(11.1)$ & $9(17.0)$ \\
\hline More than High School & $17(65.4)$ & $19(70.4)$ & $36(68.0)$ \\
\hline \multicolumn{4}{|l|}{$\operatorname{BMI}\left(\mathrm{kg} / \mathrm{m}^{2}\right)$} \\
\hline Mean \pm SD & $32.7 \pm 7.9$ & $30.4 \pm 6.0$ & $31.5 \pm 7.0$ \\
\hline Range & 23.5-51.4 & $22.8-46.1$ & $22.8-51.4$ \\
\hline \multicolumn{4}{|l|}{ OA Involvement $(n, \%)^{*}$} \\
\hline Unilateral Knee & $8(30.8)$ & $4(14.8)$ & $12(23.5)$ \\
\hline Bilateral Knee & $16(61.5)$ & $23(85.2)$ & 39 (76.5) \\
\hline \multicolumn{4}{|l|}{ WOMAC } \\
\hline \multicolumn{4}{|l|}{ Pain $^{\dagger}$} \\
\hline Mean \pm SD & $250.0 \pm 104.1$ & $238.7 \pm 124.1$ & $244.3 \pm 113.8$ \\
\hline Range & $42-422$ & $38-500$ & $38-500$ \\
\hline \multicolumn{4}{|l|}{ Stiffness ${ }^{\ddagger}$} \\
\hline Mean \pm SD & $121.2 \pm 51.8$ & $118.6 \pm 49.3$ & $119.9 \pm 50.1$ \\
\hline Range & 5-186 & 10-200 & $5-200$ \\
\hline \multicolumn{4}{|l|}{ Functional Activity ${ }^{\S}$} \\
\hline Mean \pm SD & $909.8 \pm 371.6$ & $894.7 \pm 351.8$ & $902.1 \pm 358.2$ \\
\hline Range & $151-1,408$ & $91-1,500$ & $91-1,500$ \\
\hline $\begin{array}{l}{ }^{*} \text { Significant associations between cane } \\
{ }^{\dagger} \text { Pain subscale score ranges from } 0-500 \\
{ }^{\ddagger} \text { Stiffness subscale score ranges from } 0 \\
{ }^{\S} \text { Subscale score ranges from } 0-1,700 . \\
\text { BMI = body mass index, OA = osteoart }\end{array}$ & cane nonusers at $p \leq 0.05$. & שान & 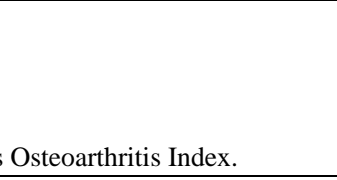 \\
\hline
\end{tabular}

PIADS subscale were not significantly different between cane users and cane nonusers or between males and females.

\section{Reliability}

\section{Test-Retest Reliability}

One-week test-retest reliability results for the CCMS are displayed in Table 4. Generally speaking, the CCMS Attitudes and Subjective Norms subscales demonstrated moderate to high test-retest reliability across cane use and sex. For all subjects across CCMS subscales, the Attitudes subscale had the highest test-retest reliability (Cronbach alpha $=0.64$ ). Conversely, the Perceived Behavioral Control subscale had poor test-retest reliability for all subjects (Cronbach alpha $=0.15)$. The Attitudes subscale demonstrated good test-retest reliability in cane users (Cronbach alpha $=0.82)$ and females (Cronbach alpha $=0.88$ ). The Subjective Norm subscale demonstrated good test-retest reliability in cane nonusers (Cronbach alpha $=0.85$ ) and 
JRRD, Volume 51, Number 2, 2014

Table 3.

Scores on Cane Cognitive Mediator Scale (CCMS) and Psychosocial Impact of Assistive Devices Scale (PIADS).

\begin{tabular}{|c|c|c|c|c|c|}
\hline Measure & $\begin{array}{l}\text { All Subjects } \\
\quad(n=53)\end{array}$ & $\begin{array}{l}\text { Cane Users } \\
\quad(n=27)\end{array}$ & $\begin{array}{l}\text { Cane Nonusers } \\
\quad(n=26)\end{array}$ & $\begin{array}{c}\text { Males } \\
(n=45)\end{array}$ & $\begin{array}{c}\text { Females } \\
(n=8)\end{array}$ \\
\hline \multicolumn{6}{|l|}{$\overline{\mathrm{CCMS}}$} \\
\hline Attitudes ${ }^{*}$ & & & & & \\
\hline Mean \pm SD & $6.5 \pm 8.5$ & $6.7 \pm 9.5$ & $6.2 \pm 7.6$ & $6.0 \pm 8.6$ & $8.9 \pm 8.3$ \\
\hline Range & $-22.0-22.0$ & $-22.0-22.0$ & $-7.0-20.0$ & $-22.0-20.0$ & $-5.0-22.0$ \\
\hline \multicolumn{6}{|c|}{ Subjective Norms ${ }^{\dagger}$} \\
\hline Range & $-32.0-40.0$ & $-24-40$ & $-32.0-38.0$ & $-32.0-38.0$ & $0-40.0$ \\
\hline \multicolumn{6}{|c|}{$\begin{array}{l}\text { Perceived Behavioral } \\
\text { Control }^{\ddagger}\end{array}$} \\
\hline Mean \pm SD & $-5.3 \pm 7.2$ & $-5.4 \pm 7.2$ & $-5.1 \pm 7.3$ & $-5.2 \pm 7.6$ & $-5.4 \pm 4.2$ \\
\hline Range & $-14.0-14.0$ & $-14.0-14.0$ & $-14.0-14.0$ & $-14.0-14.0$ & $-14.0-(-2.0)$ \\
\hline \multicolumn{6}{|l|}{ Competence $^{\S}$} \\
\hline Range & $-2.25-3.00$ & $-2.25-3.00$ & $-1.83-2.75$ & $-2.25-2.83$ & $-0.50-3.00$ \\
\hline \multicolumn{6}{|l|}{ Adaptability $^{\S}$} \\
\hline Mean \pm SD & $0.75 \pm 1.36$ & $0.99 \pm 1.53$ & $0.52 \pm 1.14$ & $0.66 \pm 1.41$ & $1.27 \pm 0.91$ \\
\hline Range & $-3.0-3.0$ & $-3.0-3.0$ & $-2.00-2.83$ & $-3.0-3.0$ & $0-2.5$ \\
\hline \multicolumn{6}{|l|}{ Self-Esteem ${ }^{\S}$} \\
\hline Mean \pm SD & $0.48 \pm 1.30$ & $0.46 \pm 1.46$ & $0.51 \pm 1.14$ & $0.42 \pm 1.25$ & $0.83 \pm 1.60$ \\
\hline Range & $-3.0-3.0$ & $-3.0-3.0$ & $-2.25-3.00$ & $-3.0-3.0$ & $-1.38-3.00$ \\
\hline \multicolumn{6}{|l|}{ Total Score } \\
\hline Mean \pm SD & $0.67 \pm 1.22$ & $0.80 \pm 1.39$ & $0.55 \pm 1.03$ & $0.58 \pm 1.22$ & $1.19 \pm 1.16$ \\
\hline Range & $-2.58-2.94$ & $-2.58-2.94$ & $-1.89-2.25$ & $-2.58-2.94$ & $-0.10-2.83$ \\
\hline
\end{tabular}

females (Cronbach alpha $=-0.93)$. The Perceived Behavioral Control subscale demonstrated fair test-retest reliability only for cane users (Cronbach alpha $=0.59$ ).

\section{Internal Consistency Reliability}

Internal consistency reliability coefficients are also displayed in Table $\mathbf{4}$ for all subjects, by cane use group and by sex. For all subjects, the internal consistency reliability of the CCMS subscales ranged from 0.79 for the Attitudes subscale to 0.93 for the Perceived Behavioral Control subscale. Internal consistency reliability for the PIADS was high on all subscales, ranging from 0.92 for the Adaptability and Self-Esteem subscales to 0.96 for the Competency subscale. Generally, internal consistency was high for both scales across cane use and sex. However, the CCMS Attitudes subscale demonstrated slightly lower coefficients ranging from 0.72 to 0.84 .

\section{Predictive Validity}

Correlations of the CCMS and PIADS subscales with use of a cane at 6 mo are displayed in Table 5. For all subjects, the CCMS Subjective Norms subscale was moderately correlated with use of a cane at 6 mo (Pearson correlation coefficient $=0.53$ ). When examined by subgroup, the CCMS Subjective Norms subscale demonstrated moderate to high correlations for cane nonusers ( $r=0.72$ ), males $(r=0.76)$, females $(r=-0.88)$, and the 45-64 yr-old age group $(r=0.74)$. For the PIADS, only the Adaptability 
Table 4.

Test-retest and internal consistency reliability coefficients of Cane Cognitive Mediator Scale (CCMS) and Psychosocial Impact of Assistive Devices Scale (PIADS).

\begin{tabular}{|c|c|c|c|c|c|}
\hline Measure & $\begin{array}{l}\text { All Subjects } \\
(n=53)\end{array}$ & $\begin{array}{c}\text { Cane Users } \\
(n=27)\end{array}$ & $\begin{array}{l}\text { Cane Nonusers } \\
\quad(n=26)\end{array}$ & $\begin{array}{c}\text { Males } \\
(n=45)\end{array}$ & $\begin{array}{c}\text { Females } \\
(n=8)\end{array}$ \\
\hline \multicolumn{6}{|l|}{ CCMS: 1-Week Test-Retest Reliability } \\
\hline Attitudes & 0.64 & 0.82 & 0.49 & 0.58 & 0.88 \\
\hline Subjective Norms & 0.48 & -0.50 & 0.85 & 0.79 & -0.93 \\
\hline Perceived Behavioral Control & 0.15 & 0.59 & -0.13 & 0.15 & 0.19 \\
\hline \multicolumn{6}{|l|}{ Internal Consistency Reliability } \\
\hline \multicolumn{6}{|l|}{ CCMS } \\
\hline Attitudes & 0.79 & 0.84 & 0.72 & 0.78 & 0.87 \\
\hline Subjective Norms & 0.92 & 0.89 & 0.94 & 0.94 & 0.58 \\
\hline Perceived Behavioral Control & 0.93 & 0.95 & 0.92 & 0.94 & 0.89 \\
\hline \multicolumn{6}{|l|}{ PIADS } \\
\hline Competency & 0.96 & 0.97 & 0.95 & 0.96 & 0.96 \\
\hline Adaptability & 0.92 & 0.94 & 0.88 & 0.94 & 0.68 \\
\hline Self-Esteem & 0.92 & 0.94 & 0.90 & 0.92 & 0.91 \\
\hline
\end{tabular}

Table 5.

Predictive validity correlations of Cane Cognitive Mediator Scale (CCMS) and Psychosocial Impact of Assistive Devices Scale (PIADS) with 6 mo of cane use.

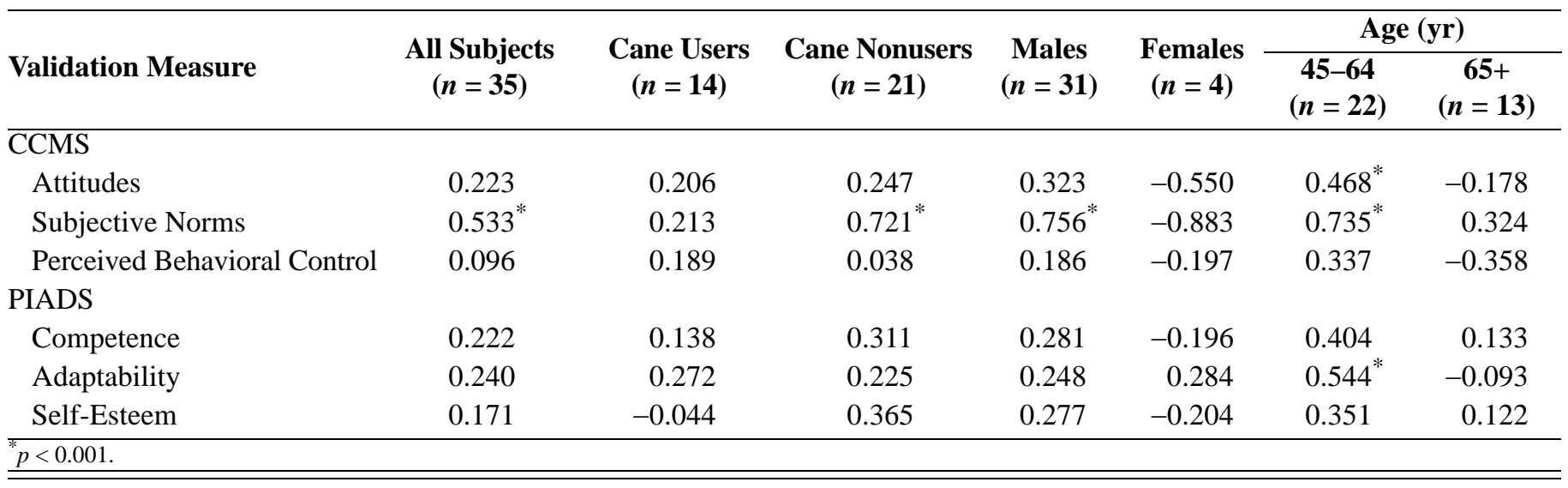

subscale demonstrated a moderate correlation with use of a cane at 6 mo for the 45-64 yr-old age group $(r=0.54)$. Both the CCMS and PIADS subscales demonstrated low predictive validity in adults $65 \mathrm{yr}$ and over, with correlation coefficient absolute values ranging from 0.17 to 0.35 for the CCMS subscales and from 0.09 to 0.13 for the PIADS subscales.

Because the CCMS Subjective Norms subscale demonstrated moderate to high predictive validity, we calculated the sensitivity and specificity of this subscale in identifying subjects who were using a cane at 6 mo. At a cutpoint of 6 , this subscale had a sensitivity of 81 percent and a specificity of 67 percent.

\section{DISCUSSION}

The aim of this study was to evaluate the reliability and validity of the CCMS and PIADS in a sample of older adults with knee OA. Both the CCMS and PIADS may be used to assess attitudes toward assistive devices regardless of whether the individual currently uses an assistive device or not. If our preliminary study demonstrates that these instruments have acceptable psychometric properties, then they might be considered for use by clinicians in screening for psychosocial factors influencing adoption of a cane or assistive device and in developing interventions to promote the use of walking aids in people with knee OA. 
The findings indicated that the CCMS Attitudes and Subjective Norms subscales demonstrated acceptable testretest reliability, with reliability coefficients ranging from 0.48 to 0.93 . The test-retest reliability was low for the CCMS Perceived Behavioral Control scale $(r=0.15)$. Test-retest reliability of the PIADS was not assessed in this study because of the data collection schedule established in the main study; however, prior studies have documented good test-retest reliability, with intraclass correlation coefficients ranging from 0.77 to 0.90 [12]. Our findings indicated that internal consistency reliability was acceptable for all CCMS and PIADS subscales for all subjects and across groups, although slightly higher for the PIADS. Our findings are consistent with prior studies that have found correlations ranging from 0.87 to 0.95 for the PIADS subscales and total score [15]. Only the CCMS Subjective Norms subscale demonstrated good predictive validity for all subjects and across subgroups. The Subjective Norms subscale measures the influence of others, such as doctors, other healthcare workers, family, and friends, on the subject's propensity to use a cane. Consistent with prior studies, our findings found that a physician's recommendation and interdisciplinary approach to evaluation significantly influence compliance [16].

Our study is the first to evaluate the psychometric properties of the CCMS and PIADS in a sample of subjects with OA and, thus, provides a starting point to investigate strategies for recommending assistive devices based on initial patient screening using these instruments. Our study results demonstrate that some subscales exhibit better psychometric properties than others, and thus, these subscales deserve further consideration for use as a screening tool. Other instruments, such as those developed by Roelands and colleagues measuring self-efficacy and intention [6], can also be explored for use as screening tools because they may be administered before actual assistive device use. Finally, because adherence requires active involvement of the patient in managing the device, initial patient screening may be combined with subsequent training strategies that are based on psychosocial factors associated with compliance.

There are several limitations to our study. First, our study was conducted on primarily male obese or overweight older adults with OA of the knee. Therefore, the results cannot be generalized to patients with normal weight or with other medical conditions. Future studies should explore the psychometric properties of these instruments in non-OA populations and across different settings. In addition, prior studies have found obesity to increase the use of assistive devices [1], so our sample may have had a greater propensity to use assistive devices than a nonobese sample.

\section{CONCLUSIONS}

Based on our findings, the application of these instruments as screening tools to identify patients with the propensity to use an assistive device for ambulation deserves further exploration. These instruments required 5-10 min for patients to complete and, therefore, are relatively easy to apply in the clinic. Their use may identify patients who are likely to be compliant with ongoing assistive device use. However, before these scales are incorporated into practice, clinicians may wish to further validate them in different patient populations and across settings. Finally, the incorporation of additional items based on other instruments may improve the ability of these instruments to determine a patient's willingness to use a device.

\section{ACKNOWLEDGMENTS}

\section{Author Contributions:}

Study design and concept: M. A. Fang, K. L. Perell-Gerson, N. Harada. Acquisition of data: C. Heiney, J. M. Yentes.

Analysis and interpretation of data: N. Harada, M. Fang, S. Fong. Obtained funding: M. Fang.

Study Supervision: J. Yentes, C. Heiney.

Financial Disclosures: The authors have declared that no competing interests exist.

Funding/Support: This material was based on work supported by the VA Office of Research and Development, Rehabilitation Research and Development Service (grant F3873R).

Institutional Review: The study was approved by the VA Greater Los Angeles Healthcare System Institutional Review Board. All participants provided written informed consent.

Participant Follow-Up: The authors do not plan to inform participants of the publication of the study because contact information is unavailable.

\section{REFERENCES}

1. Pressler KA, Ferraro KF. Assistive device use as a dynamic acquisition process in later life. Gerontologist. 2010;50(3): 371-81. [PMID:20106934] http://dx.doi.org/10.1093/geront/gnp170

2. Lauer A, Longenecker Rust K, Smith RO. ATOMS Project Technical Report. Factors in assistive technology device 
abandonment: Replacing "abandonment” with "discontinuance” [Internet]. Milwaukee (WI): ATOMS Project at the University of Wisconsin-Milwaukee; 2001 [cited 2013 Apr 12]. Available from www.r2d2.uwm.edu/atoms/archive/ technicalreports/tr-discontinuance.html

3. Jutai J, Day H. Psychosocial Impact of Assistive Devices Scale (PIADS). Technol Disabil. 2002;14:107-11.

4. Aminzadeh F, Edwards N. Factors associated with cane use among community dwelling older adults. Public Health Nurs. 2000;17(6):474-83. [PMID:11115146] http://dx.doi.org/10.1046/j.1525-1446.2000.00474.X

5. Demers L, Monette M, Lapierre Y, Arnold DL, Wolfson C. Reliability, validity, and applicability of the Quebec User Evaluation of Satisfaction with assistive Technology (QUEST 2.0) for adults with multiple sclerosis. Disabil Rehabil. 2002; 24(1-3):21-30. [PMID:11827151] http://dx.doi.org/10.1080/09638280110066352

6. Roelands M, Van Oost P, Depoorter AM, Buysse A. A social-cognitive model to predict the use of assistive devices for mobility and self-care in elderly people. Gerontologist. 2002;42(1):39-50. [PMID:11815698] http://dx.doi.org/10.1093/geront/42.1.39

7. Riddle DL, Jiranek WA, Hull JR. Validity and reliability of radiographic knee osteoarthritis measures by arthroplasty surgeons. Orthopedics. 2013;36(1):e25-32. [PMID:23276348] http://dx.doi.org/10.3928/01477447-20121217-14

8. Reginster JY, Badurski J, Bellamy N, Bensen W, Chapurlat $\mathrm{R}$, Chevalier X, Christiansen C, Genant H, Navarro F, Nasonov E, Sambrook PN, Spector TD, Cooper C. Efficacy and safety of strontium ranelate in the treatment of knee osteoarthritis: Results of a double-blind, randomised placebocontrolled trial. Ann Rheum Dis. 2013;72(2):179-86. [PMID:23117245] http://dx.doi.org/10.1136/annrheumdis-2012-202231

9. Hinman RS, Payne C, Metcalf BR, Wrigley TV, Bennell KL. Lateral wedges in knee osteoarthritis: What are their immediate clinical and biomechanical effects and can these predict a three-month clinical outcome? Arthritis Rheum. 2008;59(3):408-15. [PMID:18311763]

http://dx.doi.org/10.1002/art.23326

10. Chevalier X, Goupille P, Beaulieu AD, Burch FX, Bensen WG, Conrozier T, Loeuille D, Kivitz AJ, Silver D, Appleton $\mathrm{BE}$. Intraarticular injection of anakinra in osteoarthritis of the knee: A multicenter, randomized, double-blind, placebocontrolled study. Arthritis Rheum. 2009;61(3):344-52.

\section{[PMID:19248129]}

http://dx.doi.org/10.1002/art.24096

11. Wu CW, Morrell MR, Heinze E, Concoff AL, Wollaston SJ, Arnold EL, Singh R, Charles C, Skovrun ML, FitzGerald JD, Moreland LW, Kalunian KC. Validation of American College of Rheumatology classification criteria for knee osteoarthritis using arthroscopically defined cartilage damage scores. Semin Arthritis Rheum. 2005;35(3):197-201. [PMID:16325660] http://dx.doi.org/10.1016/j.semarthrit.2005.06.002

12. Demers L, Monette M, Descent M, Jutai J, Wolfson C. The Psychosocial Impact of Assistive Devices Scale (PIADS): Translation and preliminary psychometric evaluation of a Canadian-French version. Qual Life Res. 2002;11(6):583-92. [PMID:12206579] http://dx.doi.org/10.1023/A:1016397412708

13. Bellamy N, Buchanan WW, Goldsmith CH, Campbell J, Stitt LW. Validation study of WOMAC: A health status instrument for measuring clinically important patient relevant outcomes to antirheumatic drug therapy in patients with osteoarthritis of the hip or knee. J Rheumatol. 1988;15(12): 1833-40. [PMID:3068365]

14. PASW Statistics 18, Release 18.0.0. Somers (NY): IBM Corporation; 2009.

15. Day H, Jutai J. Measuring the psychosocial impact of assistive devices: The PIADS. Can J Rehabil. 1996;9:159-68.

16. Verza R, Carvalho ML, Battaglia MA, Uccelli MM. An interdisciplinary approach to evaluating the need for assistive technology reduces equipment abandonment. Mult Scler. 2006;12(1):88-93. [PMID:16459724] http://dx.doi.org/10.1191/1352458506ms1233oa

Submitted for publication June 14, 2013. Accepted in revised form September 18, 2013.

This article and any supplementary material should be cited as follows:

Harada N, Fong S, Heiney C, Yentes JM, Perell-Gerson KL, Fang MA. Evaluation of two cane instruments in older adults with knee osteoarthritis. J Rehabil Res Dev. 2014;51(2):275-84. http://dx.doi.org/10.1682/JRRD.2013.06.0140

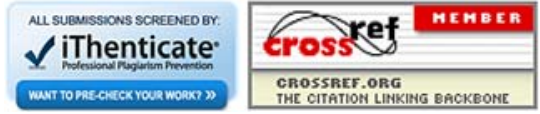


